\title{
Sex-Role Stereotyping of Nurses and Physicians on Prime-Time Television: A Dichotomy of Occupational Portrayals ${ }^{1}$
}

\author{
Philip A. Kalisch ${ }^{2}$ and Beatrice J. Kalisch \\ University of Michigan
}

Utilizing the methodology of content analysis, this study investigates the sexrole variables in prime-time television portrayals of nurses and physicians from 1950 to 1980 . A 20\% sample of 28 relevant series yielded 320 individual episodes, 240 nurse characters, and 287 physicians characters. Results show extreme levels of both sexual and occupational stereotyping. Television nurses are $99 \%$ female, and television physicians are $95 \%$ male. The cluster of sex and occupational role characteristics, personality attributes, primary values, career orientation, professional competencies, and the tone of nurse-physician relationships converge to yield an image of the female professional nurse as totally dependent on and subservient to male physicians. The development of this dichotomous sex and occupational role imagery has resulted in male television physicians who not only have outstanding medical competencies but also embrace all the attractive competencies of professional nurses. Television nurses largely serve as window dressing on the set and have little opportunity to contribute to patient welfare. Action is needed to improve the quality of nurse portrayals by making them more congruent with the real world of work in health care.

Television's chief significance as a medium has resided in its sheer impact; in its rapid infiltration into everyday American life; in the fact that its images for all their transience, smallness, sameness, and mediocrity - have wafted, year after year, into the consciousness of hundreds of millions of viewers. Television

\footnotetext{
${ }^{1}$ This study was supported by a research grant from the U.S. Public Health Service, Health Resources Administration (NU 00579).

${ }^{2}$ Correspondence should be sent to Philip A. Kalisch, Ph.D., Professor of History, Politics, and Economics of Nursing, University of Michigan, 609 East Liberty Street, Ann Arbor, Michigan 48108.
} 
presents a more or less unified vision of human experiences, such as those pertaining to nurses and physicians, a little world of its own which bears some relation to the real world, but which is inviolate and complete unto itself.

During the first two decades of research into television, the 1950 s and 1960 s, little attention was paid to the content of television programs; one very notable exception was Smythe's (1954) inventory of television programming in the early 1950s. Most researchers were much more concerned with determining the viewing patterns of the public, as if mere exposure to television were more significant than the quality of information being conveyed as a result of that exposure. Smythe's "micro-analysis" of early 1950s television contained the seeds of the future study of television content; his study, along with that of Bell (1961), sounded the keynote for subsequent analyses of television content. The content analysis of television has, in general, been concerned with defining the image of American society which is projected in television drama, with particular interest in identifying the distortions and stereotypes which television purveys to its vast audiences.

Since the late 1960s the efforts of Bell and Smythe to characterize television's image of reality have been carried forward by a great wave of research, growing in large part from increasing public sensitivity to the role of television as a social force and a communicator of ideas, and from widespread dissatisfaction with the content and quality of television (Bower, 1973). Arising from this development and abetting i.t, the techniques for objectively describing, analyzing, and comparing communications content have been explored and refined as well, so that the late-blooming study of television content has been nurtured by an increasingly enriched methodology.

Aside from the large number of studies of the levels of explicit sex and violence on television, the preponderance of the research on television content has focused on the portrayal of particular well-defined social groups. Taken as a whole, this research can be regarded as the product of the concern for social equity, or what might otherwise be described as an assault on the supremacy of the White middle class male. In particular, the studies of television content conducted in the last 10 years have been directed at television's underrepresentation of women and minority groups and its promulgation of sexual, racial, socioeconomic, and occupational stereotypes; concern over sexual stereotyping has dominated the field.

The topic of sex-role specialization in television has produced a stunning amount of research in a relatively brief time (e.g., Busby, 1975; Courtney \& Whipple, 1974; Dominick, 1979; Dominick \& Rauch, 1972; McArthur \& Eisen, 1976; McArthur \& Resko, 1975, Mills, 1974; O'Donnell \& O'Donnell, 1978; Peevers, 1979; Signorielli, 1975; Sternglanz \& Serbin, 1974; Streicher, 1974; Tedesco, 1974). This body of literature has also been documented in a bibliography by Franzwa (1978). It is possible that the problem of sexual stereotyping has received more attention than any other aspect of stereotyping because (1) the rise of the women's movement has coincided with the burgeoning interest 
in the mass media; and (2) sexual stereotyping, even in its more degrading forms, has (at least until recently) been regarded as less blatantly offensive than racial or ethnic stereotyping and has therefore persisted on television while the others stereotypes have disappeared into the netherworld of "bad taste."

The most common research approach has been demographic, since the composition of the world of television is easier to quantify than either its ambience or its values. And, in the case of television as compared to the other mass media, headcounts with respect to sex, race, age, socioeconomic status, and occupation have a particular value, since many characters are barely developed, but are seen by and make some fleeting impression upon millions of people. Also, because the world of television is such a closed one, it is possible to define it completely, on any given day, by means of a census. However, only a relatively small number of researchers have studied the attributes, values, and interactions of characters on television and such work represents the vanguard of television content analysis.

Among these studies is one by Turow (1974), who examined sexual specialization in terms of patterns of ordering and advice-giving among male and female characters in both daytime serials and prime-time dramas. He concluded that, in general, television presents a stereotyped vision of male and female expertise, thus reinforcing sex-role stereotypes. Male-female interactions are more equitable in soap operas, where the female characters issue directives in $46 \%$ of the male-female interactions; on prime-time series, men do the ordering and advising in $70 \%$ of the male-female exchanges.

A related study by Lemon (1978) analyzed the depiction of dominance in interactions between men and women in situation comedies and crime dramas broadcast during the 1975-1976 season; these two genres were chosen for high contrast with the expectation that women would be portrayed in more favorable terms in the situation comedies than in any other prime-time genre, and, conversely, women would fare worst in the male-dominated, action-oriented crime dramas. This turned out to be true, but, like Turow, Lemon found that in all programs men tend to dominate women; the margin of dominance is much higher in the crime shows, and relations between men and women are more equitable in the situation comedies, but men dominate women there too - in the home, as it were, as well as on the streets. These findings are embellished by a study which shows that females on television programs classified as violent are subjected to more pawn (controlled by others) behavior while males model more origin (exhibiting control over one's life) behavior (Hodges, Brandt, \& Kline, 1981).

Weibel's (1975) study serves as a companion of sorts to Turow's (1974) study of the patterns of advising and ordering on television drama and Lemon's (1978) and Hodge et al.'s (1981) analyses of the dominance of men over women in prime-time interactions; Weibel classified the values expressed by characters on prime-time dramatic programs in order to determine whether sexual specialization on television reflected in the characteristic association of 
different value systems with men and women. Weibel concluded that women on television are generally portrayed at lower stages of value development than men, since television's women tend to concern themselves primarily with personal happiness and interpersonal harmony, while television's men more of ten express concern for the general social good and the rights of all people. Weibel points out that most American adults would receive ratings similar to those of women on television, and Weibel suggests that her results indicate not that the average television male is more moral than his female counterpart, but that television portrays a higher number of exceptional men than it does exceptional women. Certain professional classes are especially susceptible to idealization - physicians in particular - and on television these professions are largely populated by men.

Frueh and McGhee (1975) and McGhee and Frueh (1980) suggested that children, particularly heavy viewers, may actually attend more to TV portrayals of sexual stereotyped activities than to nonstereotyped activities, a finding supported by the results of Drabman, Robertson, Patterson, Jarue, Hammer, and Cordua (1981) and Mankiewicz and Swerdlow (1977-1978), who conducted experiments in which children claimed that a videotape or film showing a man acting as a nurse and a woman acting as a doctor had actually presented a male doctor and a female nurse. Beuf (1974) found that children's sex-role perceptions acquire traditional shape very early in life, a phenomenon that she relates to television viewing.

The problem of sexual stereotyping or specialization is a very broad and very deep field of inquiry with rich possibilities not yet fully explored. In addition to this subject and related to it has been a secondary area of investigation into television's deployment of occupational stereotypes. The actual attributes of occupational stereotypes have barely been touched upon. The primary emphases of the inquiry into occupational stereotyping have been the overrepresentation of working women and their confinement to certain stereotyped forms of feminine employment. Various studies cited above support these criticisms of television content on the grounds of sexual stereotyping; in addition, several studies have focused upon the world of work on television (De Fleur, 1964, Seggar \& Wheeler, 1973).

Seggar and Wheeler (1973) examined the relative representation of various ethnic and occupational groups (both men and women) on television. In addition, the authors compared their data with information from the U.S. Census Bureau regarding the actual presence of the groups they discussed within the American populace. They found that the number of TV portrayals per group. generally did not accurately reflect the presence of the group in the national population; women are "grossly underpresented"; minority groups are more consistently portrayed in service occupations and areas more likely to be depicted in stereotypical terms; the presentation of both sexes tends to be stereotypical, but the portrayal of women is even more limited in range than the depiction of men. 
De Fleur based his investigation of televisions portrayals of occupations upon 436 individual appearances of characters on screen. His most interesting finding concerns the relative power of the various occupations portrayed in his study. He surveyed children with respect to qualities that render a job attractive to them, and found that power over others exerted the strongest appeal to children. De Fleur ranked the occupations analyzed in the study in terms of the power associated with them, basing his power ratings upon such measures as mode of address and order giving. De Fleur's ranking of occupational groups in terms of their relative power and prestige on television placed nurses virtually at the bottom of the scale, with a -100 rating and a rank of 32 out of 34 occupations. As one might expect, physicians ranked relatively high - in ninth place, with a power rating of 96 .

Nurses have been especially prominent among the female workforce of the world of television, precisely because television tends to rely more heavily than other media upon stereotypes, and nursing is a stereotypically feminine profession. The U.S. Commission on Civil Rights (1979) reported that for the years 1975-1977, the majority of female characters seen on television (40.1\%) were shown having no occupation. When they were shown in occupations, registered nurses (RNs) constituted the second most frequent occupation in which women were portrayed $(7.2 \%)$. The only other occupational group exceeding RNs for TV females was the nonprofessional field of secretarial work $(7.3 \%)$.

The relationship of the physician to the nurse is an issue that encompasses the processes of both sexual stereotyping and occupational stereotyping. The literature cited here has substantiated and developed television's tendency to stereotypification, as well as affirming a connection between television viewing and the acceptance of television's interpretation of human experience.

With respect to physicians and nurses, the evidence suggests that television entertainment tends to glorify the male professional, and the physician perhaps more than any other professional - has benefited from this process. The purpose of this study is to determine the nature and extent of the differences in prime-time television portrayals of nurses and physicians over the past three decades and to illuminate the major variables implicit in the interface between the sexual and occupational stereotypings of the two largest groups of health care professionals.

\section{METHOD}

\section{Sample}

This study was confined to the prime-time series with major nurse and physician characters which appeared on television from 1950 to 1980. 
These series were identified for inclusion in the study by reviewing each weekly issue of the New York City edition of TV Guide from 1950 to 1980. Once a series was identified as appropriate for the study, individual episodes were gathered from archives and other sources. The aim was to collect the videotape or final shooting script of each episode of the relevant series and then to randomly select $20 \%$ of the annual number of episodes for the series' duration.

In order to test the comparability of the video and script versions in terms of measurement reliability, 20 video programs for which we also had the scripts were coded. The data were then subjected to agreement analysis and resulted in a $94.2 \%$ agreement between the video and script versions. Twentyeight different series, 320 individual episodes, 240 nurse characters, and 287 physician characters were analyzed in the study.

\section{Research Instruments}

Three content analysis tools were developed and tested for coding the messages about nurses and nursing in television programs: One dealt with the overall episode, another centered on the nurse character, and the third tool provided analysis of the physician character. The Unit Analysis Tool contained variables which addressed dominant impressions of nursing in a given episode. It included items on objective actions of the total group of nurse characters appearing in the television programs as well as subjective impressions conveyed by the narrator comment, behavior of other characters, filming technique, and the situational contexts in which the characters were presented.

The Nurse Character and Physician Character Analysis Tools were used to collect data on the portrayals of these characters in each episode. Questions dealt with the extent of the character's role in the episode, the objective physical attributes and behavior of the character, and the subjective impressions created by context, comment, and filming techniques.

Coders underwent a standardized training program developed for the project. Intrarater reliability was determined by having $5 \%$ of the sample coded twice several months apart by the same coder. Intrarater reliability across all coders and all items was $88.4 \%$. Interrater reliability was determined by having all coders analyze $20 \%$ of all the television episodes in the study. Interrater agreement among all coders was $90.2 \%$.

Content validity was established by an inductive and additive process of classifying all aspects of the image of the nurse and nursing which were found to exist in television programming until all categories of new phenomena had been exhausted. Instruments were then reviewed by a panel of experts and subsequently modified prior to actual data collection.

Convergent validity was estimated by testing the ability of certain measurement items in the data instruments to predict others in an expected or 
hypothesized fashion. For example, $92 \%$ of TV series coded as hospital dramas were also coded as showing nurses working in a hospital setting; $100 \%$ of the nurse characters who stated that nursing constitutes a patriotic service were also coded as appearing in military drama or comedy. Nurses who were shown in administrative roles were also portrayed as having power and influence over others $(r=.54, p<.01)$. There was a significant association between the extent to which nurse characters were seen helping patients and the degree to which they provided emotional support to patients and families $(r=.54, p<.01)$.

\section{Reliability and Validity of Image Constructs}

Since our purpose was to capture an integrated, composite image of television nurse characters, and given that it was easier to deal conceptually and mathematically with a few indices rather than with multiple variables, several different analytic procedures (factor analysis or principal component analysis) were used to condense variables into a smaller number of factors representing statistical parsimony. Each construct reported in this analysis was subjected first to reliability testing via estimation of the extent to which it exhibited internal consistency. All constructs produced a coefficient alpha of at least .69. Split-half reliability was also estimated by random assignment of items. within a given construct to one of two groups, followed by canonical correlation between the two sets of measures. All constructs were found to exhibit split-half reliability of at least $.58, p<.05$. Then each construct was submitted to predictive validity testing to determine the extent to which it corresponded with some external criterion measure logically expected to be related. For example, the factor Assertiveness correlated significantly with being tough $(r=.64, p<.001)$ and energetic $(r=.54, p<.0001)$.

\section{RESULTS}

\section{Demographic Characteristics}

Television nurse characters were generally female (99\%), Caucasian (95\%), under 35 years of age (43.6\%), single (82\%), and childless (95\%). The demographic profile projected by television has not changed significantly in 30 years. When exceptions to this profile were in evidence, the nurse characters were often presented in a somewhat unfavorable light. For example, the only male nurse seen in the sample (Nurse Newton of "A.E.S. Hudson Street," 1978) was the object of subtle jokes and innuendos regarding his sexual preference. Older nurses were significantly less attractive $(t(228)=6.02, p<.001)$ and tended to 


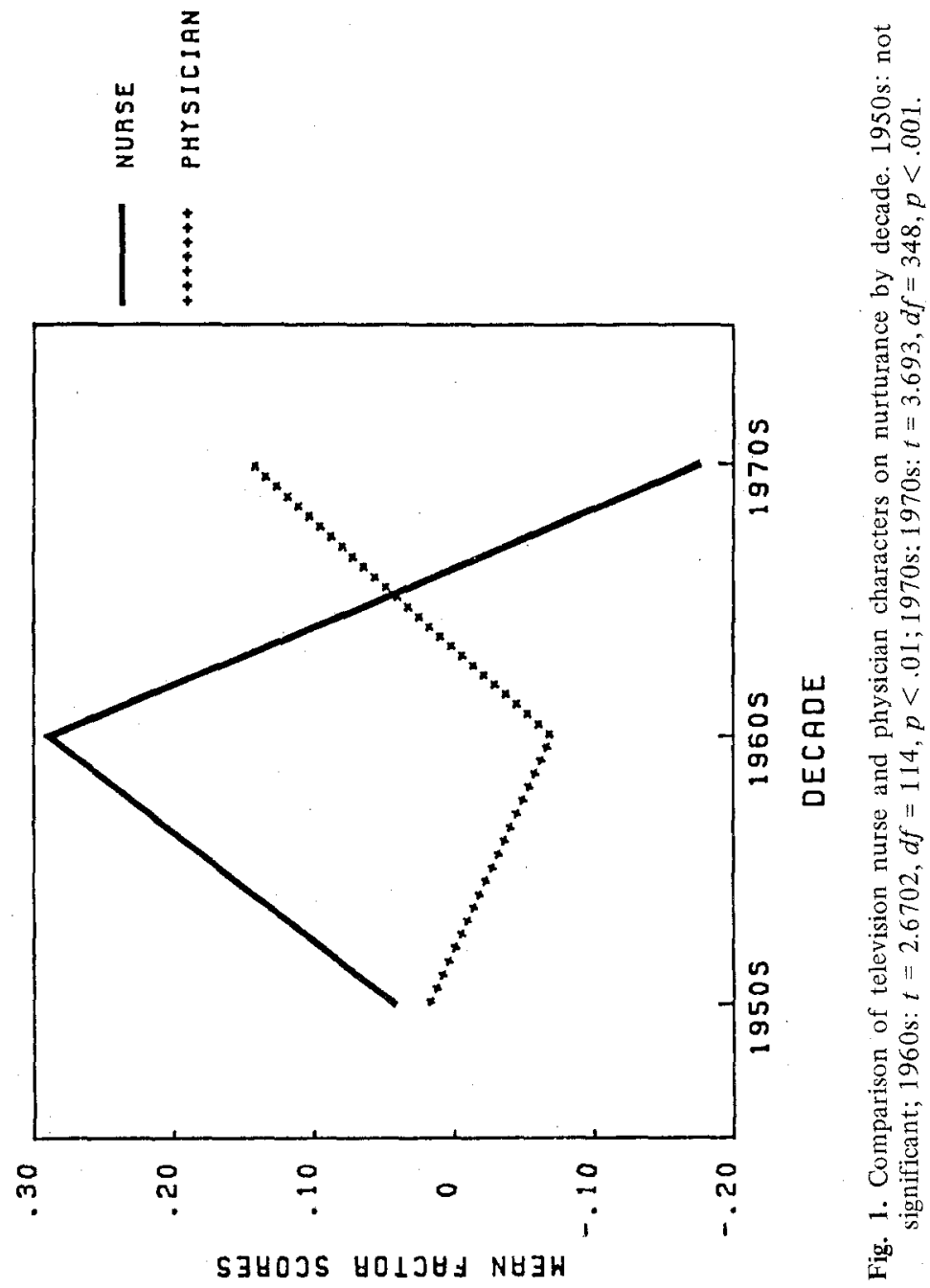


be more sadistic and reprimanding towards patients than their younger colleagues $(t(234)=1.85, p<.06)$.

Television physicians, on the other hand, were older $\left(\chi^{2} \mathrm{ml}=94.12\right.$, $\phi=.39, d f=4, p<.0001)$ and more often parents $\left(\chi^{2} \mathrm{ml}=13.67, \phi=.16, d f=\right.$ $1, p<.001)$. Gender provided the most striking contrast, as physicians were overwhelmingly male ( $95 \%$ ). Although there has been very little effort to portray men as nurses, there has been a growth, albeit small, in the number of female physicians appearing on the television screen. The 1950 s found no women physicians, 2 (2.8\%) were found in the 1960s sample, and the 1970s sample contained $13(6.9 \%)$ female physicians. As was true for the sample of nurse characters, only $3.9 \%$ of physician characters represented minority groups.

\section{Centrality of Role}

Physician characters have consistently been presented as more central to the dramatization than nurse characters (Mann-Whitney $U=13203, N=$ $524, p<.0001$ ). Nurse characters are typically relegated to supporting roles, which conveys a message to the viewer that nurses are simply not essential in heal th care.

\section{Personal Attributes and Primary Values}

A set of 23 personal attributes was subjected to factor analysis followed by varimax rotation. Four identifiable and conceptually meaningful factors were identified: Nurturance, Individualism, Benevolence, and Assertiveness. Nurturance had high loadings on flexibility (.67), warmth (.64), permissiveness (.63), sociability (.63), and kindness (.51). Many of the highest loadings on Individualism were negative - obedience $(-.61)$, discipline $(-.49)$, conformity $(-.49)$ - followed by positive loadings on aggressiveness (.46) and risk taking (.40). Benevolence loaded highest on sincerity (.80), honesty (.74), kindness (.67), altruism (.65), and warmth (.48). Assertiveness reflected high loadings on confidence (.74), aggressiveness (.71), rationality (.59), sophistication (.53), and risk taking $(.50)$.

Nurturance, as exhibited by both physicians and nurses, has followed an interesting trajectory. As seen in Figure 1, RNs and medical doctors (MDs) were depicted as equally nurturant in the 1950s, but nurses were significantly more nurturant in the 1960 s and significantly less nurturant in the 1970s. In terms of individualism, MDs exhibited significantly more of this trait in both the decades of the 1960s and 1970s (see Figure 2). Nurses were consistently portrayed as exhibiting more benevolence than MDs (see Figure 3), and television physician characters were consistently shown as more assertive than nurse characters (see Figure 4). 


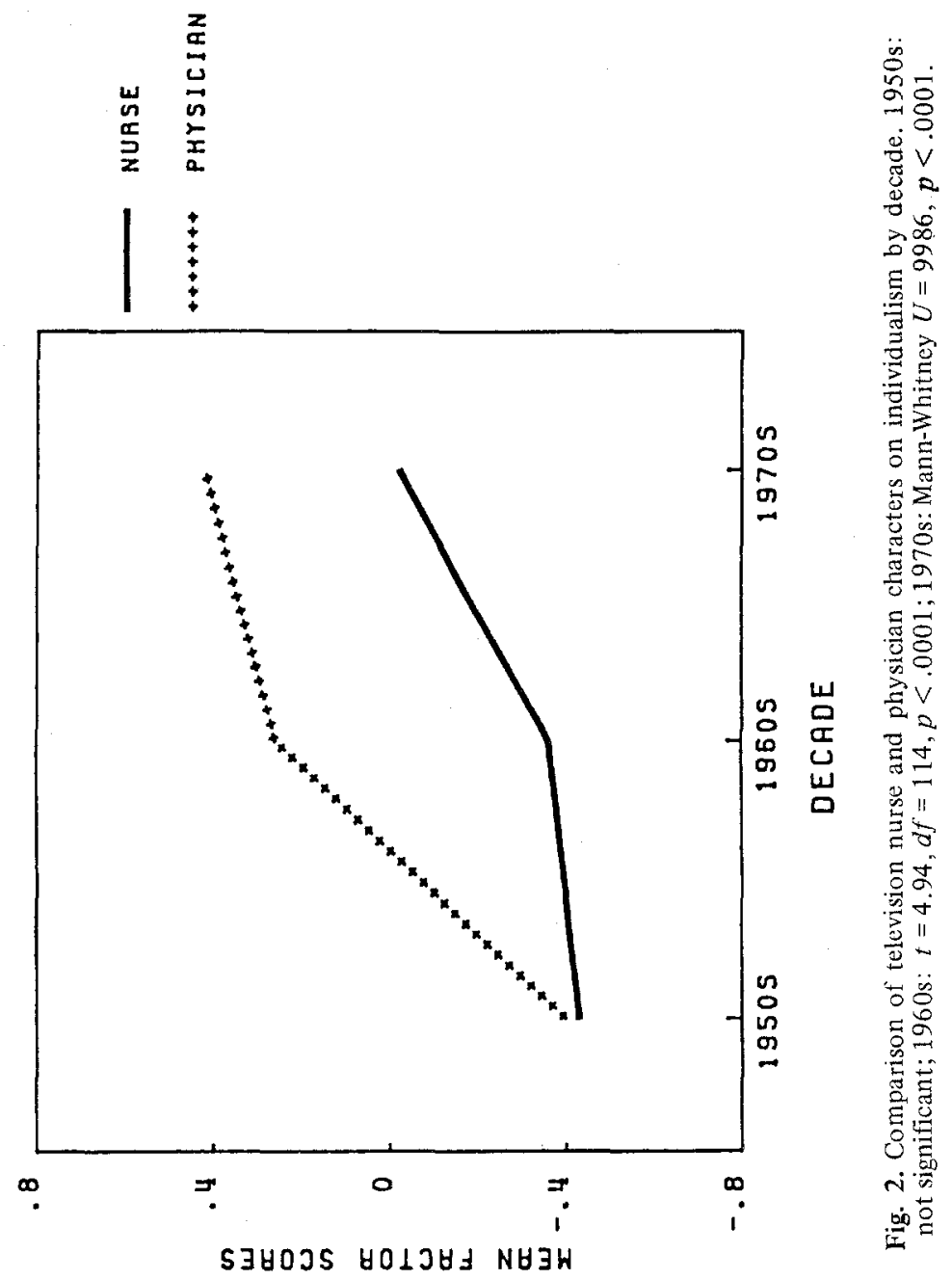




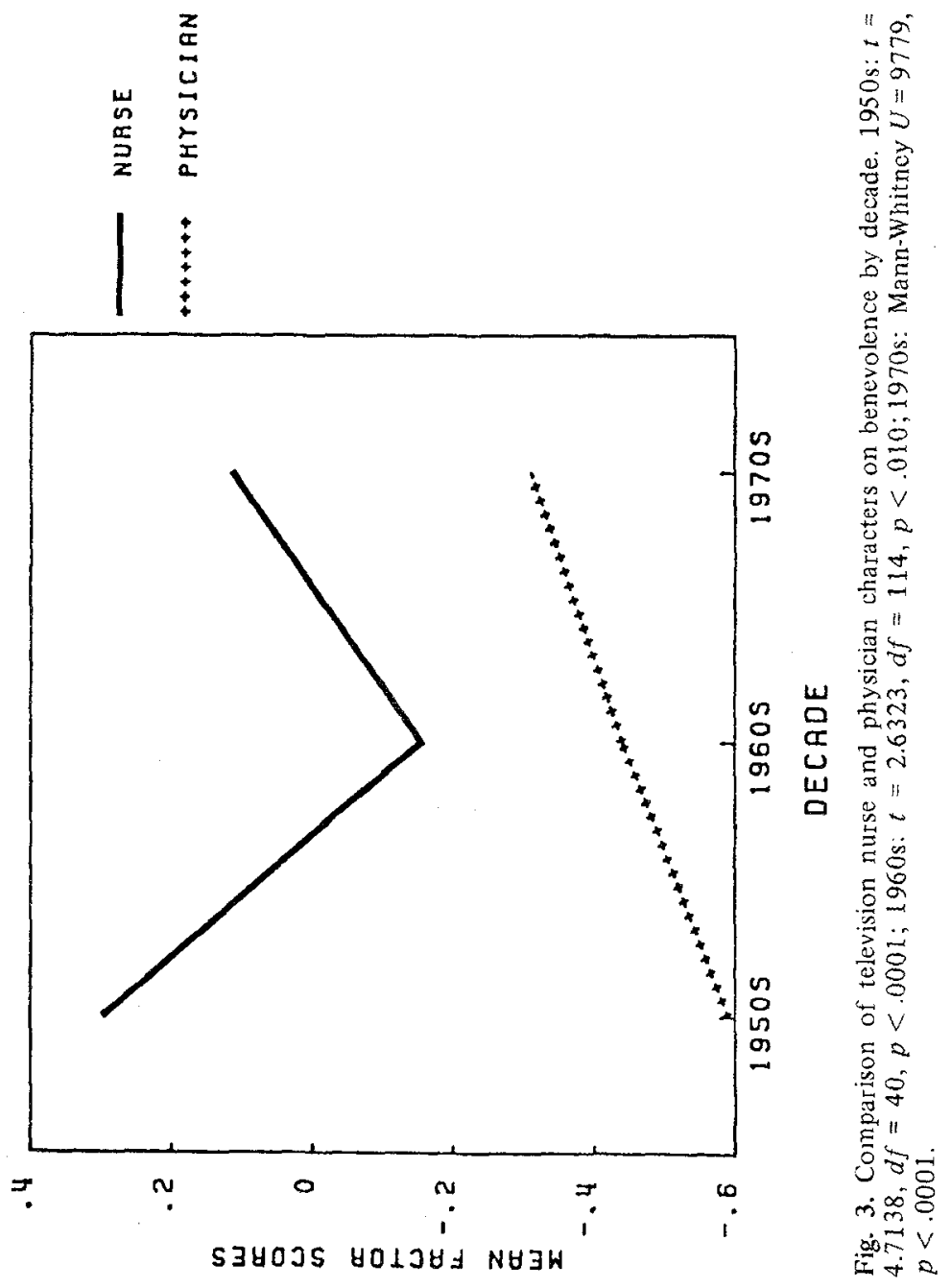




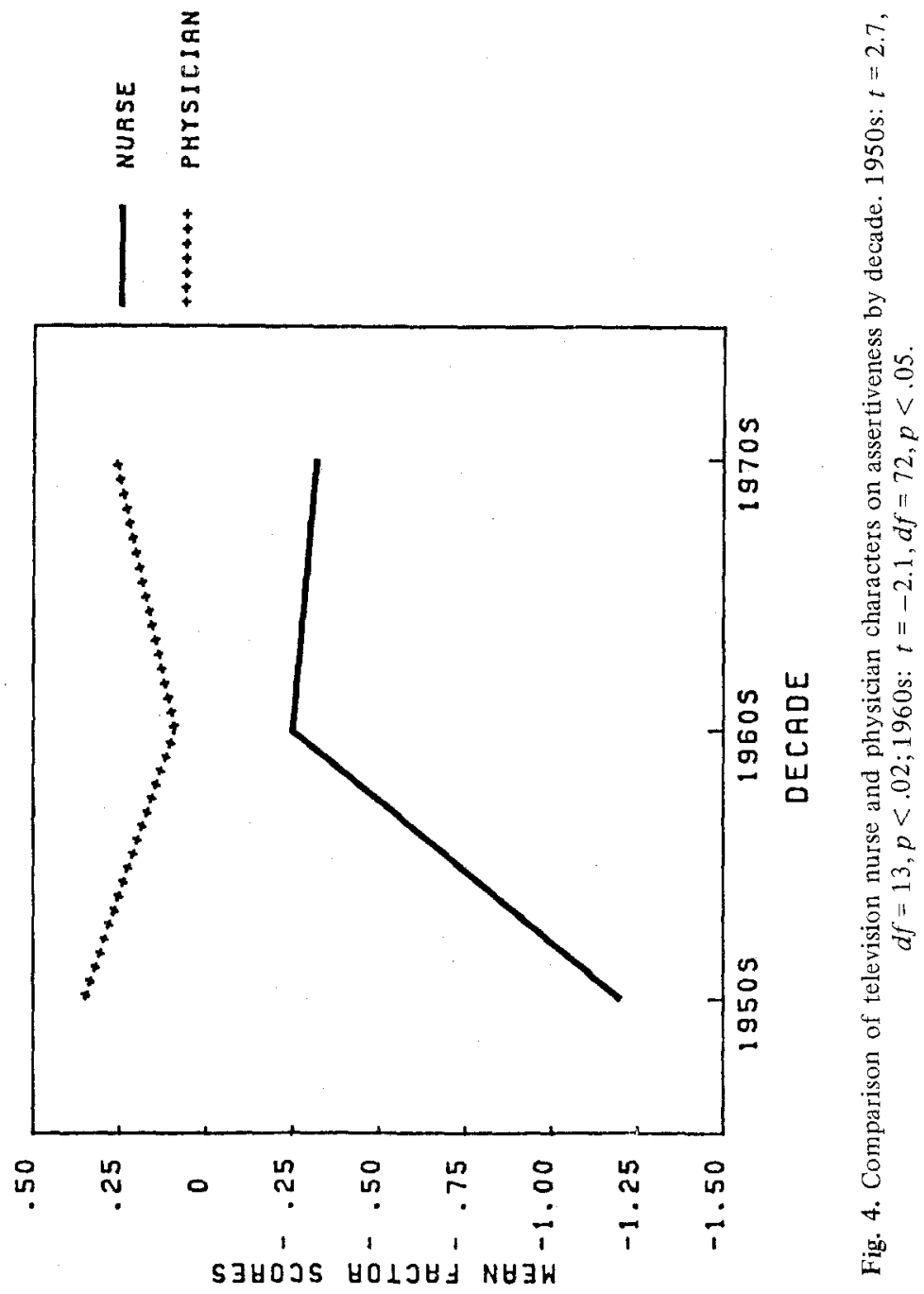




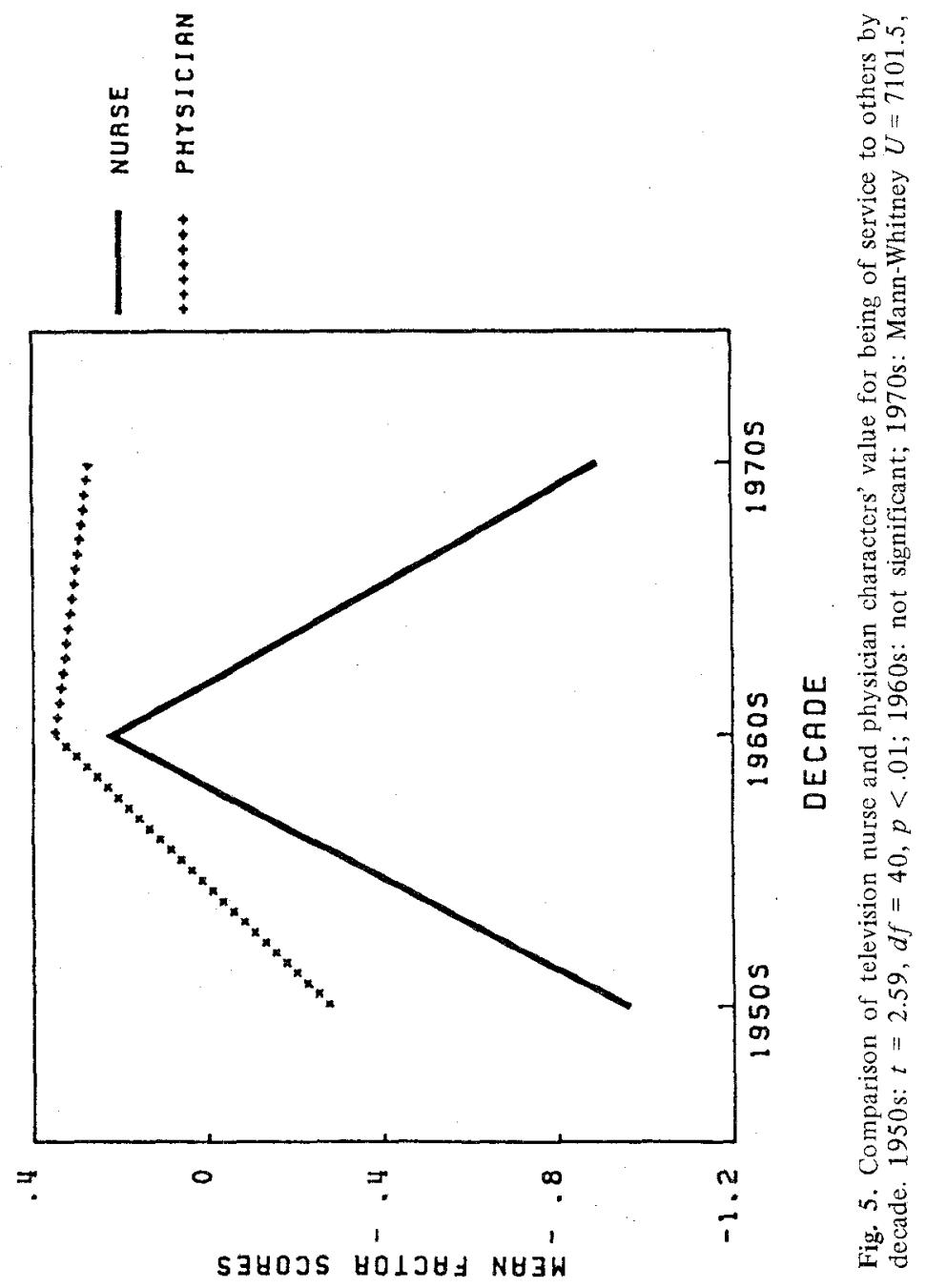




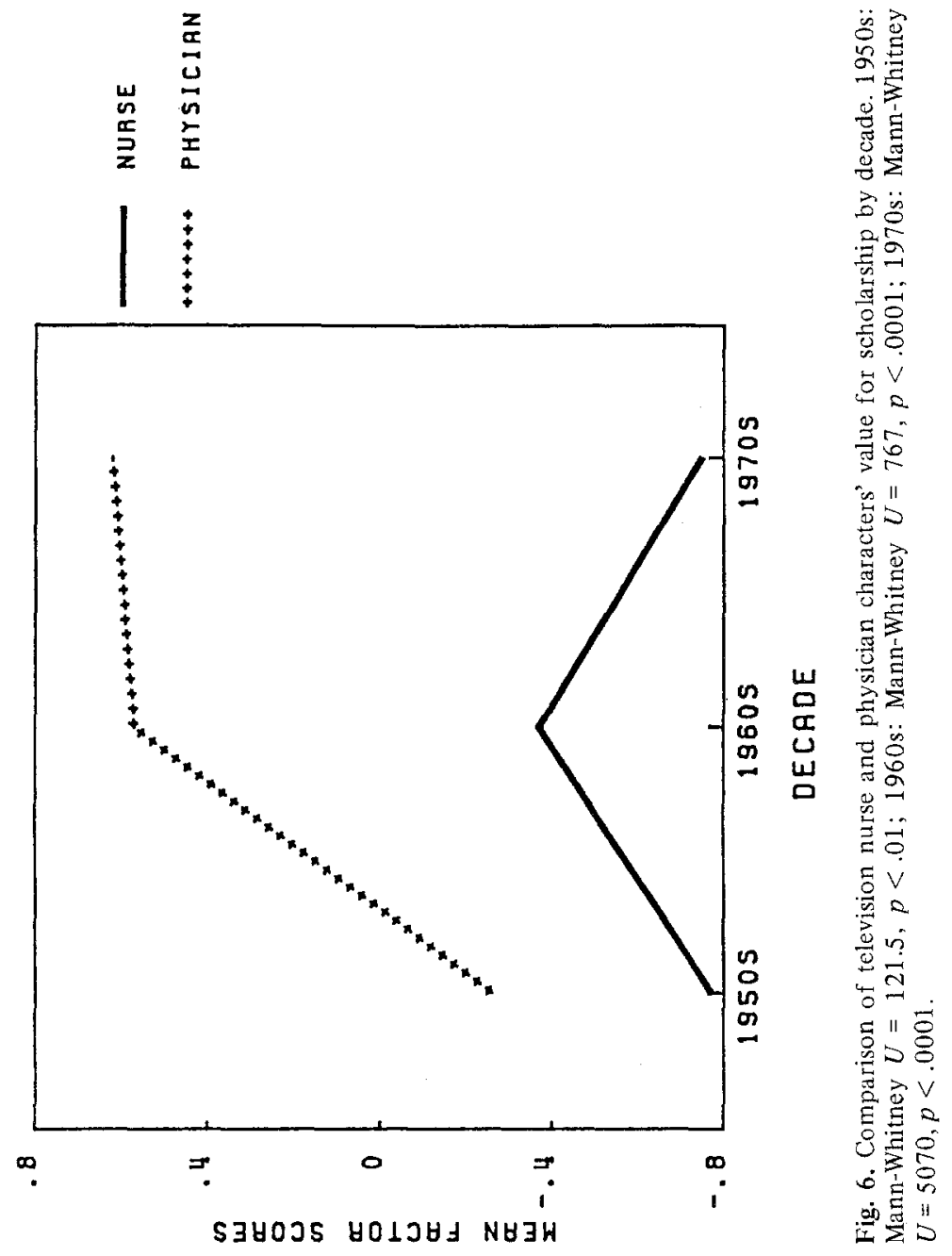




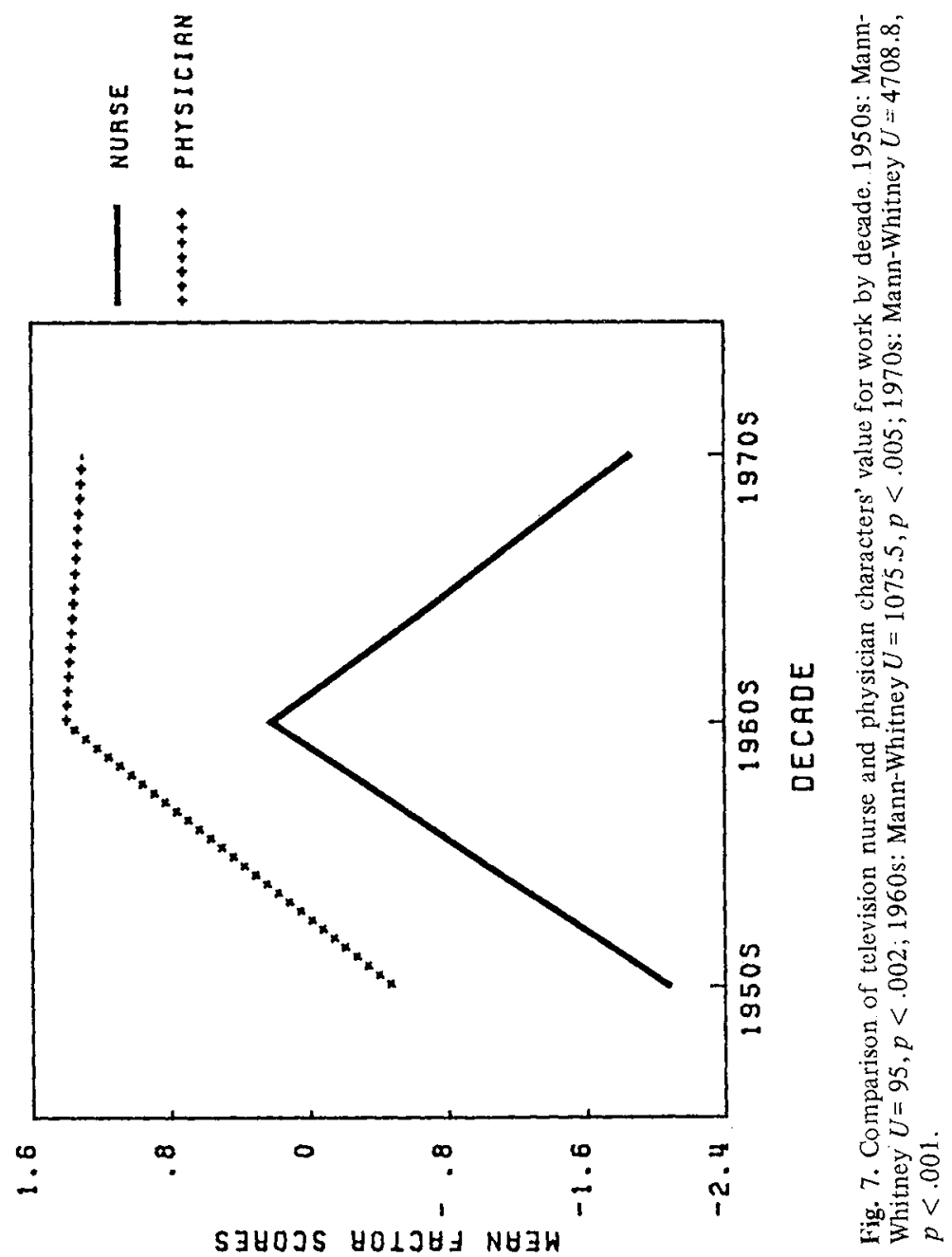


Principal components analysis yielded three primary value constructs derived from a set of 14 variables. The first value construct was "service to others," which loaded high on value for duty (.47), integrity (.47), self-sacrifice (.46), and commitment to making the world a better place (.43). "Scholarship," the second component to emerge, reflected high loadings on intellect (.60), science (.61), and achievement (.51). Value for "work" loaded highest on integrity (.72), duty (.67), self-sacrifice (.64), and achievement (.59). In comparisons of television nurse characters with physician characters for value of service to others, MDs scored significantly higher in the 1950s and 1970s (see Figure 5). RN and MD characters did not differ in the 1960s. Physicians value scholarship and work significantly more than nurses across all decades (see Figures 6 and 7).

\section{Career Orientation}

Several study variables measured aspects of the career orientation of nurses and physicians. Physician characters saw their career as significantly more important to their lives than nurse characters did (Mann-Whitney $U=$ 16856, $N=400, p<.01$ ). MDs were also commended more for their professional behavior than RNs $(t(527)=4.01, p<.0001)$, and the attitudes of other characters were significantly more positive toward physician characters than nurse characters (Mann-Whitney $U=4142.5, N=521, p<.0001$ ). In terms of change over time, nurse characters were commended more in the $1960 \mathrm{~s}$ $(F(2,190)=3.16, p<.05)$ and expressed the highest degree of job satisfaction during this decade (Kruskal-Wallis $H=9.45, N=221, p<.01$ ).

\section{Professional Competence}

Perhaps the most crucial question in the portrayal of any health professional on television is the extent to which practitioners are seen contributing to patient welfare. Nurse characters were shown helping patients significantly less than their physician counterparts $(t(440)=7.80, p<.0001)$. The difference was especially dramatic in the 1970s $(t(239)=8.33, p<.0001)$. Television nurses in the 1960 s contributed the most to patient welfare, showing a sharp upward rise from the 1950s $(F(2,166)=3.17, p<.04)$. During each decade, nurse characters were also portrayed as using their own judgment in patient care situations far less than television physicians (in each decade the Mann-Whitney $U$ statistic yields $p<.001$ ).

The various nursing activities that television nurse characters were seen performing as part of the professional role were divided into three categories: (1) those associated with the traditional nursing role (e.g., physical comforting, bedmaking), (2) those associated with a progressive role (e.g., taking a health 
history, resuscitating a patient), and those which fall into both traditional and progressive areas of practice (e.g., giving medications, taking vital signs). Traditional activities were portrayed significantly more often than either progressive activities (paired $t(238)=7.81, p<.0001$ ) or the mixed traditional/progressive activities (paired $t(238)=4.69, p<.0001$ ).

\section{Nurse-Physician Relationships}

The tone of nurse-physician relationships on television has been characterized as largely that of nurse as handmaiden to physician. Physicians view nurses as inferiors rather than equals (paired $t(287)=7.82, p<.0001$ ). Physicians issued orders far more often than they consulted nurses (paired $t(168)=16.74$, $p<.0001$ ). Although nurses have assumed greater responsibility in health care over the three decades studied, the 1970s tended to show nurse-physician colleagueship as even lower than the 1950 s $(F(1,183)=3.67, p<.06)$. Similarly, physicians' respect for nurses declined significantly during the $1970 \mathrm{~s}(F(2,225)=$ $3.92, p<.02)$ and disharmony between television nurse and physician characters dropped from the 1960 s to the $1970 \mathrm{~s}(F(1,205)=5.1, p<.03)$. It is interesting to note that physicians commended nurses significantly more than nurses commended each other (paired $t(239)=8.56, p<.0001$ ). Physician characters, on the other hand, commended and criticized one another equally; nurses were twice as likely to praise an MD as to criticize him.

\section{Nurse as Sex Object}

The instrument contained 12 items designed to capture various aspects of the presentation of the nurse as sex object, such as the extent to which sex appeal was played up, character's value of sex, and prominence of sexual activity as a behavioral trait in the character. Since a single composite measure was desired, principal component analysis was used to create a Sex Object Index score for each nurse character. Figure 8 illustrates that emphasis on the nurse as sex object has escalated dramatically over the past 30 years. The more nurse characters have been presented as sex objects, the less they have been shown expressing a serious commitment to making the world a better place $(r=-.20$, $p<.01)$ and the less they have been seen in their professional role $(r=-.36$, $p<.001)$.

\section{DISCUSSION}

The findings of this study point to the fact that the contribution of the nurse to health care as portrayed on television has been distinctly underplayed 


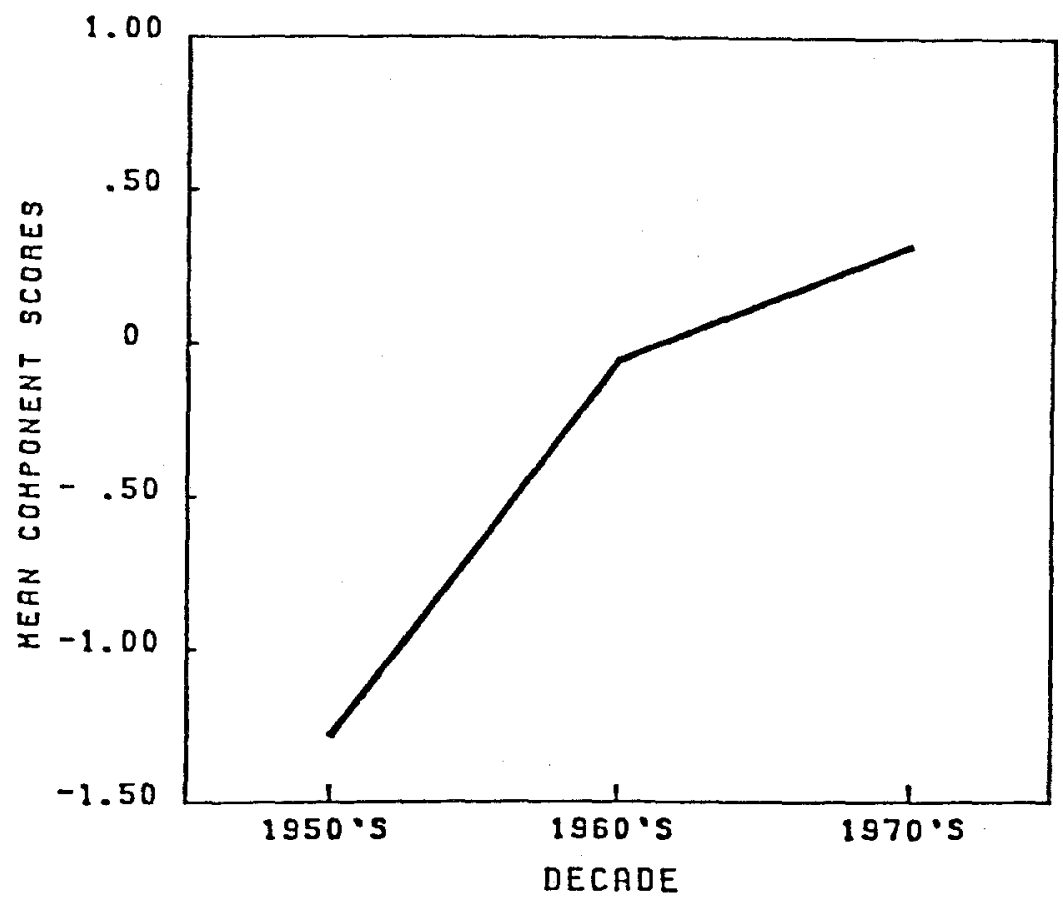

Fig. 8. Emphasis on television nurse characters as sex objects by decade. KruskalWallis $H=7.70, p<.02$.

and, conversely, the role of the physician has been presented in an exaggerated, idealistic, and heroic light. Nurse characters are presented as less central than physician characters to the dramatizations. Nurses are shown to be less committed and happy with their profession than MDs. Nurses are viewed less positively by other characters, and are portrayed as if they make a far smaller contribution to patients' well-being and as if they are incapable of autonomous judgment. When nursing activities are shown on television, the traditional ones (which more accurately reflect the role of the nurse in the early 1950s) dominate. There has been very little attempt, particularly in the 1970s, to show the central and diverse role the nurse plays in the delivery of health care to the public.

In terms of personal attributes, not only were 1970s television physicians presented as maintaining a stronghold on the traditional male traits of individualism and assertiveness but they also exceeded television nurse characters in nurturance, one of the most positive traditional images of the nursing profession. This was exemplified by the portrayal of "Marcus Welby, M.D.," a physician routinely shown providing all of the nursing as well as medical care. Similarly, primary values of TV physicians not only reflect the traditional male-oriented values but also the more traditionally female-oriented value of service to others. 
No concomitant gain in the portrayal of nurses is evident; nurses on TV have not assumed a more androgynous personality and value system.

When the data are reviewed over time, it is noteworthy that the 1950 s series portrayed physicians as similar to nurses in terms of nurturance and individualism. Then, in the 1960s, when the first wave of television medical drama hit the nation, the portrayal of physicians took a decided turn. Television physicians were no longer kindly and unselfish. Instead, as in the "Ben Casey" model, they were portrayed as omniscient, omnipotent, ubiquitous, and self-righteous. Thus, their individualism scores rose, while nurses' remained low.

The sharp 1960s rise in nurse nurturance, value for service to others, value for scholarship and positive contribution to patient welfare, was due to one series, "The Nurses," which aired on CBS from 1962 to 1965. This was the only series to actually focus on the profession of nursing in the three decades studied, and it offered television audiences a view of nurses at work minus the domineering presence of physicians. Nursing was consistently portrayed as an autonomous profession with its own standards and values, which equalled those associated with the medical profession. Nurse characters turned to each other rather than to male physician characters to solve their problems. During the 1960s, televison MDs showed more respect for RNs, and nurse-physician colleagueship was higher as well as disharmony - indicating that nurses were important enough in health care to have opinions and express them openly. In the 1970s, when real-life nurses' technical competencies, knowledge base, and educational preparation had reached their highest level, the television image was largely one of the nurse as subservient to the physician and the nurse as a sex object.

Nurses are virtually always presented as female and physicians as male, reinforcing the stereotype that nursing is "women's work." Inasmuch as females are now entering traditionally male-dominated fields in large numbers, and given the declining number of female high school graduates, the fact that nursing is still $98 \%$ female augurs poorly for an adequate supply of professional nurses for the nation. A severe nurse shortage, estimated at over 100,000, existed in 1982; the perpetuation of negative stereotypes and the lack of television portrayals of male nurses are undoubtedly adding to this problem.

While both nurses and physicians are theoretically part of the "health care team," sex-role stereotypes have combined with occupational stereotypes on television to cement the nurse in to a current subsidiary role as the "physicians" handmaiden." To a large extent the media creation process has perpetuated this outcome across the three decades of television history, as the audiences were limited to the insights into the nursing and medical professions that television offered. The result has been that the occupational possibilities of real nurses have been severely constrained by the absence of media-generated reinforcement, while those of physicians have been maximized with extraordinary support from the television industry. 
Television entertainment programming always transforms or re-creates reality. The television picture is a medium and, because a medium expresses by means of its own qualities and colorations, it can transform identifiable groups such as nurses and physicians into "smaller than life" or "bigger than life." Because of formula-like repetitions of the behaviors of nurse and physician characters, prime-time television series have become burdened with predictable story lines. As the most widespread form of mass communication, television may act as both a mirror and a lamp. Television not only may reflect the "reality" of professional contributions but also may light the way to new contributions. It is essential for the future of health care in this nation that television begin to light the way for nurses and nursing even if this does diminish the intensity of the artificial halo that the television physician has worn for 30 years.

\section{REFERENCES}

Bell, R. M. A study of the image of the American character as presented in selected network television dramas. Doctoral dissertation, Ohio State University, 1961.

Beuf, A. Doctor, lawyer, household drudge. Journal of Communication, 1974, 24, 142-145. Bower, R. T. Television and the public. New York: Holt, 1973.

Busby, L. J. Sex-role research on the mass media. Journal of Communication, 1975, 25, $107-131$.

Courtney, A. E., \& Whipple, T. W. Women in TV commercials. Journal of Communication, $1974,24,110-118$.

De Fleur, M. Occupational toles as portrayed on television. Public Opinion Quarterly, $1964,25,54-74$.

Dominick, J. R. The portrayal of women in prime time, 1953-1977. Sex Roles, 1979, 5, 405-411.

Dominick, J., \& Rauch, G. E. The image of women in TV commercials. Journal of Broadcasting, 1972, 16, 259-265.

Drabman, R. S., Robertson, S. J., Patterson, J. N., Jarvie, G. J., Hammer, D., \& Cordua, G. Children's perceptions of media-portrayed sex roles. Sex Roles, 1981, 1, 379389.

Franzwa, H. The image of women in television: An annotated bibliography. In Hearth and Home, ed. Tuchman, G., Daniels, A. K., \& Benet, J. New York: Oxford University Press, 1978, 272-299.

Frueh, T., \& McGhee, P. E. Traditional sex role development and amount of time spent watching television. Developmental Psychology, 1975,11, 109.

Hodges., K. K., Brandt, D. A., \& Kline, J. Competence, guilt, and victimization: Sex differences in attribution of causality in television drama. Sex Roles, 1981, 7, 537-546.

Lemon, J. Dominant or dominated? Women on prime-time television. In G. Tuchman, A. Kaplan, \& J. Benet (Eds.), Hearth and home. New York: Oxford University Press, 1978. Pp. 116-129.

Mankiewicz, F., \& Swerdlow, J. Sex roles in TV: Co-opted liberation. Television Quarterly, $1977-1978,14,7$.

McArthur, L. Z., \& Eisen, S. V. Television and sex-role stereotyping. Journal of Applied Social Psychology, 1976, 6, 329-351.

McArthur, L. Z., \& Resko, B. G. The portrayal of men and women in American television commer cials. Journal of Social Psychology, 1975, 97, 209-220.

McGhee, P. E., \& Frueh, T. Television viewing and the learning of sex-role stereotypes. Sex Roles, 1980, 6, 1980, 6, 179-188.

Mills, K. Fighting sexism on the airwaves. Journal of Communication, 1974, 24, 150-155. 
O'Donnell, W. J., \& O'Donnell, K. J. Update: Sex-role messages in TV commercials. Journal of Communication, 1978, 28, 155-158.

Peevers, B. H. Androgyny on the TV screen? An analysis of sex-role portrayal. Sex Roles, $1979,5,797-809$.

Seggar, J. F., \& Wheeler, P. World of work on TV: Ethnic and sex representations in TV drama. Journal of Broadcasting, 1973, 19, 201-214.

Signorielli, N. Men and women in television drama: The use of two multi-variate techniques for isolating dimensions of characterization. Doctoral dissertation, University of Pennsylvania, 1975.

Smy the, D. Reality as presented by television. Public Opinion Quarterly, 1954, 18, 143-156.

Sternglanz, S. H., \& Serbin, L. A. Sex role stereotyping in children's television programs. Developmental Psychology, 1974, 10, 710-715.

Streicher, H. W. The girls in the cartoons. Journal of Communication, 1974, 24, 125-129.

Tedesco, N. S. Patterns in prime time. Journal of Communication, 1974, 15, 55-64.

Turow, J. Advising and ordering: Daytime, primetime. Journal of Communication, 1974, $24,138-141$.

U.S. Commission on Civil Rights. Window dressing on the set. Washington, D.C.: U.S. Government Printing Office, 1979.

Weibel, K. P. Life styles and ethical values of men and women on television, 1960-1974. Doctoral dissertation, Michigan State University, 1975. 